\title{
LAS TIC EN HONDURAS: UN ANÁLISIS SOCIOTÉCNICO
}

\author{
ICTS IN HONDURAS: A SOCIOTECHNICAL ANALYSIS
}

Fátima K. Espinoza-Vasquez

Recibido: 04/05/2018 - Aceptado: 18/05/2018

\begin{abstract}
Resumen
Se presenta un análisis de las tecnologías de información y comunicación (TIC) en Honduras y su relación con los cambios sociales. Se emplea metodología de caso de estudio y se usa un marco teórico sociotécnico. Se encontró que el golpe de Estado del 2009 marcó un giro en el uso de las TIC. Los medios sociales y los medios masivos alternativos vieron un auge debido a la severa polarización social. Por otro lado, el aparato estatal adoptó nuevas formas de vigilar la sociedad civil y creó nuevas políticas de control de las TIC. Se concluye que proteger de la estructura descentralizada de las TIC es crucial para la democracia hondureña.
\end{abstract}

Palabras clave: Tecnologías de comunicación en información, TIC, Honduras, democracia, sociedad civil, sistemas sociotécnicos.

\begin{abstract}
This article presents an analysis of information and communication technologies (ICTs) and their relation to social change in Honduras. The study employs a case study methodology and a sociotechnical theoretical framework. Findings indicate that the 2009 coup d'état marked a turning point in the use of ICTs in Honduras. Social media and alternative media use increased due to heavy social polarization. On the other hand, the State adopted new ways of spying on civil society and created new policies to control ICTs. The paper concludes that protecting the decentralized structure of ICT is crucial for Honduran democracy.
\end{abstract}

Keywords: Information and Communication Technologies, ICTs, Honduras, Democracy, Civil Society, Sociotechnical Systems. 


\section{Introducción}

Las tecnologías de la información y de la comunicación (TIC), sobre todo las basadas en el internet, se han considerado cruciales para salir del "subdesarrollo económico" y fortalecer los procesos democráticos. Los informes del Programa de las Naciones Unidas para el Desarrollo (PNUD) y el Banco Mundial (BM) se han enfocado en los beneficios que las TIC pueden traer a la economía y a la democracia. Es por ello que su adopción e implementación han sido muy impulsadas por el modelo neoliberal de desarrollo. Algunos estudios científicos al respecto han identificado tres áreas en las cuales las TIC influyen la democracia y la política de un país, por medio del uso que les da la sociedad civil.

\section{Las estructuras políticas e instituciones estatales}

Las TIC ayudan a que la sociedad civil alcance audiencias más diversas y globales (Bennett y Toft, 2009; Van Laer y Van Aelst, 2010). Debido a que las TIC permiten diseminar información en forma muy rápida y a un menor costo, para la sociedad civil es más fácil cubrir extensos territorios, con lo cual se promueve la creación de redes de solidaridad e identidades colectivas más amplias (Nagel et al., 2010; Shumate y Pike, 2006). Asimismo, brindan nuevas formas de participar en procesos democráticos, a través de comunidades en línea, foros, revistas ciudadanas, entre otros (Riemer, 2003; Walgrave, et al., 2011; Weissberg, 2003, Howard, 2011).

Aunado a lo anterior, conviene decir que este tipo de tecnologías le facilitan a la sociedad civil crear y mantener redes sociales más heterogéneas, las cuales les permiten tener acceso a una mayor diversidad de perspectivas (Bennett, 2012; Garrett, 2006; Hsu, 2009; Van Laer y Van Aelst, 2010). Además, contribuyen a aumentar la actividad transnacional, por lo que su nivel de influencia se magnifica (Diani y McAdam, 2003; Bennett y Toft, 2009); ayudan a que la información fluya con menos restricciones, lo cual facilita su acceso y la creación de conciencia entre potenciales aliados dentro de las elites locales (Hess, 2007; Loudon, 2010; Vinthagen, 2011); y le dificulta al Estado el control y la censura de información (Bratich, 2011; Garrett, 2006; Juris y Pleyers, 2009; Pickerill, 2009; Spaeth et al., 2008; Espinoza-Vasquez, 2015).

Así las cosas, las TIC ayudan a que la sociedad civil influya y participe en procesos institucionales, por consiguiente, hacen que los sistemas políticos sean más pluralistas, lo cual propicia democracias más saludables.

\section{La actividad contenciosa, la composición y estructura organizacional de la sociedad civil}

En relación con este asunto, las TIC potencian la capacidad de difundir información organizacional, con lo cual se alcanzan más y muy diversos miembros (Juris, 2012) 
y se aumenta el número de causas a las que estas pueden unirse (Walgrave, et al., 2011). Además, aumentan el control que la sociedad civil y los ciudadanos en general tienen sobre su propia exposición a información, lo cual les permite ser más selectivos y estratégicos con la información a la que acceden (Garrett, 2006; Pilisuk, et al., 1996; Gladwell y Shirky, 2011).

Las TIC incrementan el repertorio de contención con nuevas tácticas de protesta (Eltantawy y Wiest, 2011; Gerbaudo, 2012; Hess, 2011; Joss Hands, 2011; Sádaba, 2012; Squire y Gaydos, 2013) y patrones de movilización (Olesen, 2004; Riemer, 2003; Van Laer, 2010; Vinthagen, 2011). Estas ayudan a crear y a mantener vínculos interpersonales e interorganizacionales (Della Porta y Diani, 1999; Walgrave, et al., 2011), con lo cual se brinda la posibilidad de fortalecer comunidades locales y transnacionales (Bennett y Toft, 2009; Maireder y Schwarzenegger, 2012; Van Laer y Van Aelst, 2010; Hayhurst y Wilson, 2011). Promueven la adopción de estructuras organizacionales descentralizadas, las cuales las hacen más aptas para actividades colaborativas (Juris, 2012; Castells, 2000; Morris y Mueller, 1992; Garret, 1996; Aalto-Matturi, 2005). Lo anterior apunta a que, gracias a las TIC, la forma en que la sociedad civil se organiza ha evolucionado.

\section{Los marcos interpretativos, las TIC}

Han reducido el costo de los recursos necesarios para producir y difundir contenido. Esto facilita la diseminación de contenido y perpetúa la disponibilidad de información (Van de Donk et al., 2004; Bratich, 2011; Wollenberg, et al., 2006; Bennet y Segerberg, 2012; Hogan, et al., 2010). De esta misma manera, dan más control editorial a la sociedad civil, con lo cual se evita la distorsión introducida por los filtros de los medios de comunicación masiva (Juris y Pleyers, 2009; Scott, 2001).

En consecuencia, las TIC promueven una cultura participativa en la cual las habilidades de comunicación, persuasión y socialización son fundamentales para los miembros de la sociedad civil (Bennett y Segerberg, 2012; Biddix, 2010; Bratich, 2011; Castells, 2000; Dunbar-Hester, 2010; Postigo, 2012).

Los hallazgos son muy valiosos. Sin embargo, se observa que la mayoría de los estudios revisados adoptaron un enfoque tecnológico determinista. Es decir, asumieron que las TIC provocan los cambios en la sociedad, lo cual los lleva a presuponer que existe una relación causal directa entre las TIC y la transformación social. Estos enfoques deterministas asumen que la tecnología es una entidad autónoma que se desarrolla de acuerdo con una lógica interna, por lo cual su uso siempre trae los resultados esperados (Russell y Williams, 2002). En ese sentido, no advierten que la implementación de las TIC puede traer consigo consecuencias no deseadas.

Aunque es indudable que las TIC afectan las propiedades y los objetivos de la sociedad, ese efecto es más dinámico que directo. Dicho de otra manera, los cambios sociales suceden como resultado de acciones situadas y estratégicas que son influenciadas 
por relaciones sociales, valores, relaciones de poder y tecnologías. Así pues, las personas son quienes le dan importancia y significado a las TIC; y los puntos de vista de las personas (situados en un contexto dado) determinan cómo son utilizadas. Por lo tanto, existen consecuencias no deseadas, las cuales son provocadas por el uso de las TIC, y su impacto varía con el contexto.

Así las cosas, este artículo utiliza un enfoque teórico que toma en cuenta no solo las TIC en sí mismas, sino también el contexto sociopolítico, las relaciones sociales y los valores. El documento se organiza de la siguiente manera: primero, se presenta el marco teórico y la metodología que guía el estudio; segundo, se realiza una descripción cronológica sobre el desarrollo de las TIC en Honduras, la cual se centra en los eventos más sobresalientes de cada década; y, finalmente, se presenta una discusión en torno al rol actual y el futuro de las TIC en ese país.

\section{Marco teórico}

Para estudiar el caso de las TIC en Honduras, se necesita un enfoque holístico y multidisciplinario que utilice múltiples niveles de análisis. De manera que se propone un marco dinámico y sociotécnico, el cual logra explicar los mecanismos a través de los cuales las estructuras sociales, los procesos organizacionales, los significados colectivos y las TIC interactúan recíprocamente y se influyen entre sí.

Dicho marco parte del Modelo de Política Contenciosa (MPC) de McAdam et al. (1996), el cual, aunque fue creado para el estudio de los movimientos sociales, es idóneo para entender fenómenos sociales, porque asume una relación recíproca entre las estructuras institucionales, el potencial de movilizar recursos y las competencias, identidades, experiencias y actitudes que moderan las acciones de la sociedad civil.

El nivel macro, denominado Estructuras de Oportunidad, consiste en las disposiciones institucionales del entorno político que modelan la expresión y la participación política. Estas son las disposiciones oficiales que brindan, entre otras cosas, oportunidades para votar, hacer campañas, formar partidos políticos y celebrar asambleas públicas (Della Porta, et al., 1999; Kriesi, 2004; McAdam et al., 2001; Tarrow, 2011; Meyer, 2004; Espinoza-Vasquez, 2013). Por ejemplo, se encuentran las políticas e instituciones gubernamentales, la legislación, los cambios en la economía, los precedentes históricos y los cambios en las políticas públicas.

El segundo nivel, llamado Estructuras de Movilización, se refiere a la infraestructura organizacional o a las redes de asociación existentes que le permiten a los individuos y a los grupos organizarse y participar en acciones colectivas (Davis et al., 2005; Granovetter, 1973; McAdam et al., 2001; Reitzes y Reitzes, 1987; Schwartz y Paul, 1992; McCarthy, 1996; Davis y Zald, 2005; Davis, McAdam, Scott y Zald, 2005; McCarthy y 
Zald, 1977; Kriesi, 2004; Cogburn y Espinoza-Vasquez, 2011). En este caso, se observa la estructura y los procesos de organización de grupos como las organizaciones de la sociedad civil, las iglesias, los sindicatos, las redes de activistas, las organizaciones vecinales, incluso, las amistades.

El tercer nivel, denominado Marcos Interpretativos, trata los esfuerzos estratégicos grupales para crear realidades y entendimientos compartidos que motivan la acción colectiva (Benford y Snow, 2000; McCammon, 2013; McAdam et al., 1996). Los marcos interpretativos son creados mediante la adopción de discursos relevantes al entorno social. A este nivel, se examinan las narrativas que dan sentido al entorno e impulsan a la gente a tomar decisiones y a participar en acción colectiva.

El marco dinámico sociotécnico usado en esta investigación propone una extensión del MPC para poder incorporar las TIC en el análisis. Se parte del supuesto de que las TIC tienen características materiales que posibilitan ejercer acciones para las cuales fueron diseñadas. Sin embargo, quienes les brindan importancia y significado son los seres humanos; y sus puntos de vista, situados en un contexto dado, en última instancia determinan cómo son usadas. Por lo tanto, se incorporan las TIC en todos los niveles propuestos por el MPC.

A nivel macro, se analiza la configuración de las TIC como infraestructura para entender su rol moderador, ya sea facilitando o limitando la expresión y participación política. Se utilizan parámetros como la centralización, la distribución, la regulación y el nivel de control. Además, se analizan datos como las estadísticas de uso, la penetración y la propiedad, asimismo, información sobre el marco regulatorio general.

En el nivel medio, se analizan los tipos y el uso de las TIC en el ámbito organizacional, para entender su rol en la creación y el soporte de redes y organizaciones de la sociedad civil. Se analizan, por ejemplo, qué tipo de TIC son usadas y cuáles prácticas acompañan su uso. Lo anterior incluye prácticas como la búsqueda de información y el uso de tecnologías como el internet.

En el nivel micro, se analiza el rol de las TIC en la creación y diseminación de marcos interpretativos y narrativas. Se explora el significado que los grupos les dan a las tecnologías y cómo este significado está conectado con su uso y contexto. También, se identifican marcos interpretativos específicos basados en las narrativas creadas por la gente que utiliza las TIC.

\section{Metodología}

Esta investigación fue realizada por medio del uso de la metodología del estudio de caso, en la cual se recaudaron diversos tipos de información en cada nivel de análisis. Se realizaron entrevistas semiestructuradas en un amplio grupo de informantes claves, 
entre los cuales se incluyen activistas, miembros de la sociedad civil nacional, del gobierno, de organismos internacionales y de los medios de comunicación. Las entrevistas fueron confidenciales, de manera que a los informantes se les asignó un seudónimo de acuerdo con su rol (por ejemplo, activista, sociedad civil, medios, entre otros). La diversidad de participantes permitió obtener una amplia gama de perspectivas.

Las personas participantes fueron seleccionadas a partir del método de muestreo de bola de nieve, el cual reduce la posibilidad de coacción y el sesgo (Creswell, 2013; Yin, 2009). Se realizaron preguntas acerca de sus experiencias usando las TIC. También se recopilaron documentos, registros y material audiovisual disponibles públicamente en internet; entre estos se encuentran estadísticas oficiales sobre TIC, noticias, informes oficiales, blogs, sitios web, videos, y fotografías. Posteriormente, se generaron descripciones que se convirtieron en una narrativa cronológica, la cual interconecta los tres niveles de análisis. Esta cronología ayuda a identificar la relación entre los conceptos y los niveles de análisis, además, facilita la creación de una narrativa holística que explica la relación dinámica entre las TIC, las organizaciones y el contexto hondureño.

\section{Las TIC en Honduras}

De acuerdo con el marco dinámico sociotécnico, para entender las TIC es necesario comprender tres niveles. Estos tres niveles se analizan y se presentan simultáneamente en intervalos de tiempo específicos, conectados secuencialmente. Se inicia en la década de los años ochenta y se presta especial atención al golpe de Estado que se llevó a cabo en el año 2009; puesto que dicho suceso ilustra claramente el impacto de las políticas de TIC en la democracia.

\section{La primera mitad del siglo $\mathrm{XX}$}

El desarrollo de las telecomunicaciones en Honduras se estancó en el siglo $\mathrm{XX}$, gracias, en parte, a la inestabilidad política del país y a que un buen número de regímenes militares y dictatoriales ejercieron políticas de proteccionismo, control y centralización de las telecomunicaciones. Entre 1900 y 2018 hubo, al menos, cinco golpes de Estado ${ }^{1}$ y nueve dictaduras y gobiernos militares. ${ }^{2}$ La mayoría de estos gobiernos centralizaron el control sobre los medios de comunicación, a través del ente regulador.

Las TIC "tradicionales", como el teléfono y la radio, llegaron a Honduras en la primera mitad del siglo XX. En $1932^{3}$ se automatiza la telefonía, mientras que la radio llega en 1921. ${ }^{4}$ Aunque se fundaron varias radio-operadoras en el ámbito comunitario, HRN (1933) y Radio América (1948) se establecieron como las emisoras más prominentes, 
con lo cual dominaron las ondas de radio AM y FM a lo largo y ancho del país. Por su parte, la televisión llegó treinta años después, en el año de 1959. ${ }^{5}$ De la misma manera, Emisoras Unidas, la propietaria de HRN, creó una red de estaciones en todo el país agrupadas en la Corporación Televicentro, con lo cual se consolidó como el principal monopolio de radio y televisión del país.

En $1976^{6}$ se funda Empresa Hondureña de Telecomunicaciones HONDUTEL, la empresa estatal encargada de la regulación de los servicios de telecomunicaciones del país; la principal y, durante mucho tiempo, la única operadora autorizada de telefonía. Controlada durante la mayor parte de su existencia por las fuerzas armadas, HONDUTEL fomentó un régimen que limitó la expansión de la radio y la televisión y perpetuó el monopolio de la telefonía durante décadas. La radio permaneció como uno de los medios de comunicación más importantes del país; por muchas décadas, fue el único medio masivo que llegaba a las comunidades más remotas y desatendidas.

\section{El regreso a la democracia y la implementación de medidas neoliberales en los años ochentas}

En 1981, Honduras realizó elecciones generales y retornó al orden republicano constitucional democrático. Sin embargo, a pesar de haber creado reglas democráticas, a través de la emisión de una nueva Constitución de la República, no funcionó como una democracia efectiva. Lo anterior se debió, por una parte, a que los dos partidos tradicionales se diferenciaban muy poco entre sí en lo ideológico, por lo que, perpetuaron políticas conservadoras y proteccionistas, y, por otra parte, a que los militares continuaron siendo la institución más poderosa e influyente del país.

Esta orientación conservadora se vio favorecida por el hecho de que durante esta década Honduras fue convertida en la retaguardia de la guerra norteamericana contra los sandinistas nicaragüenses (Ullman, 1983). El gobierno de los Estados Unidos, a través de la Agencia Central de Inteligencia (CIA), entrenó y proporcionó suministros al ejército hondureño y al grupo contrarrevolucionario nicaragüense conocido como los "Contras". Militares entrenados en la Escuela de las Américas se convirtieron en los líderes del ejército, con lo cual se incrementó su capacidad combativa y represiva. Entre 1982 y 1984, estas organizaciones fueron responsables del surgimiento de los escuadrones de la muerte, la desaparición de más de 179 personas y de una larga lista de violaciones de derechos humanos (Gill, 2004; Brocket, 2005; Ullman, 1983).

El BM, la Organización de las Naciones Unidas y la Organización de Estados Americanos también tuvieron una fuerte presencia en Honduras, incluso, una influencia más fuerte en el gobierno que la sociedad civil local. Presionaron al gobierno para la creación de leyes que se ajustaran a los acuerdos internacionales 
en materia de consolidación de la paz, protección de la democracia, de las libertades fundamentales y de los derechos humanos. Hacia el final de la década, el Fondo Monetario Internacional (FMI) y el BM prescribieron un conjunto de medidas económicas destinadas a promover la actividad económica, aumentar los ingresos del gobierno, mejorar las carreteras, la educación y la atención médica (Ullman, 1983; Leonard, 2011).

Así pues, a través de una serie de Programas de Ajuste Estructural (PAE), el gobierno (bajo el presidente nacionalista Rafael Leonardo Callejas) liberalizó el comercio, abrió las fronteras para la inversión extranjera directa y promovió la privatización de empresas estatales, incluso HONDUTEL. Todas estas medidas tuvieron su mayor impacto en el sector de las telecomunicaciones durante la siguiente década.

\section{La liberalización del mercado de telecomunicaciones en la década de los noventa}

En la década de 1990, Honduras ingresó a la Iniciativa de Países Pobres Altamente Endeudados (IPPAE), impuesta por el FMI y el BM. Como consecuencia, el Estado hondureño comenzó una segunda ronda de PAE, la cual fue apoyada por todos los partidos políticos (Almeida, 2015). La sociedad civil local formó coaliciones para luchar contra estas medidas, la más importante fue el Bloque Popular (Prevost, et al., 2012; Boussard, 2003, Calix Rodriguez, 2003). A pesar de la oposición de la sociedad civil, los PAE fueron implementados y tuvieron un impacto significativo en el sector de las TIC.

El presidente Rafael Leonardo Callejas aprobó el 31 de octubre de 1995 la Ley Marco del Sector de Telecomunicaciones, con la cual promovió la desregulación de algunos mercados en el sector de las telecomunicaciones, permitió la apertura del sector a la inversión privada y sentó las bases para la futura privatización de HONDUTEL (Tábora, 2007). Esta ley también eliminó, en teoría, el control militar de HONDUTEL y transfirió toda la responsabilidad de las políticas de telecomunicaciones, primero al Congreso Nacional y luego, en 1997, mediante el Decreto 118-97, al presidente de la República. La mayor parte del sector de telecomunicaciones fue liberado, abriendo las puertas del mercado de la telefonía celular a compañías locales e internacionales. Esto creó la necesidad de un ente regulador, la Comisión Nacional de Telecomunicaciones (CONATEL), encargada de supervisar el desarrollo y operación de las telecomunicaciones en Honduras.

\section{HONDUTEL y la telefonía fija}

Bajo la sombrilla de la "Ley Marco de Telecomunicaciones", la ley orgánica de HONDUTEL fue modificada para permitir su privatización. El Estado retendría el $47 \%$ de capital de la empresa, los trabajadores un $2 \%$ y el operador o socio estratégico 
internacional un 51 \% (Tábora, 2007). Se suponía que HONDUTEL competiría con los proveedores privados y se esperaba que se privatizara por completo dentro de diez años. Sin embargo, estos planes cambiaron debido al impacto económico del huracán Mitch en 1998.

Cuando finalmente HONDUTEL se abrió para capitalización privada en el año 2000, el proceso de licitación fracasó porque la única oferta recibida (por parte de TELMEX) fue significativamente menor al precio solicitado por el gobierno. Se estableció un nuevo plazo para que HONDUTEL renunciara a su exclusividad en las líneas fijas en 2005; sin embargo, no se cumplió este plazo porque las directrices de las licitaciones gubernamentales fueron imprecisas e insuficientes (Comisión de la Verdad y Reconciliación, 2011). HONDUTEL se convierte de esta manera en proveedor de teléfono fijo, internet y de telefonía celular.

\section{La telefonía celular}

La primera empresa de telefonía móvil comenzó operaciones en 1996. Otras compañías ingresaron al mercado varios años después, en intervalos de 4 años aproximadamente. El aumento de competencia bajó los precios y el celular rápidamente dejó de ser un artículo de lujo y se convirtió en una necesidad. La penetración aumentó consistentemente durante esta primera década, pero despuntó después del año 2006, con la presencia de cuatro compañías en el mercado.

\section{La radio}

Después de la liberalización de las telecomunicaciones, surgieron pequeñas estaciones locales propiedad de cooperativas, pueblos indígenas, sindicatos y organizaciones de la sociedad civil en todo el país, especialmente en comunidades remotas. Estas radios vinieron a llenar un vacío de información en las comunidades desatendidas por las corporaciones.

La voz Lenca, en el departamento de Intibucá, y la Radio Guarambala, eran las radios estrictamente ligadas a las organizaciones populares indígenas del departamento, específicamente COPINH [Consejo Popular de Organizaciones Indígenas] y la ONIL [Organización Nacional Indígena Lenca] (Activista 8). 
Tabla 1

PENETRACIÓN CELULAR EN HONDURAS DE 1996 A 2017

\begin{tabular}{lc}
\hline Año & Porcentaje de penetración celular \\
\hline 1996 & 0.04 \\
1997 & 0.24 \\
1998 & 0.57 \\
1999 & 1.25 \\
2000 & 2.39 \\
2001 & 3.57 \\
2002 & 4.79 \\
2003 & 5.43 \\
2004 & 10.04 \\
2005 & 18.01 \\
2006 & 30.61 \\
2007 & 55.52 \\
2008 & 79.56 \\
2009 & 106.53 \\
2010 & 118.13 \\
2011 & 96.15 \\
2012 & 86.87 \\
2013 & 89.71 \\
2014 & 87.69 \\
2015 & 89.82 \\
2016 & 85.95 \\
2017 & 88.87 \\
\hline
\end{tabular}

Fuente: CONATEL y BM.

\section{La televisión}

Después de la liberalización del mercado, surgieron también estaciones de televisión pequeñas alrededor del país. Estas estaciones "alternativas" cubrieron la necesidad de contenido local y son propiedad en su mayoría de pequeñas empresas, periodistas independientes y organizaciones religiosas. Sin embargo, a diferencia de la radio, después de la liberalización del mercado Televicentro mantuvo una presencia más fuerte en la televisión.

\section{El internet}

Internet llegó a Honduras a principios de la década de 1990. Inicialmente, HONDUTEL era el único proveedor de servicios de internet; sin embargo, poco después, 
había docenas de operadores. Hacia finales de los años noventa, el servicio se expande y se abarata a medida que las compañías de cable y de celular ingresaban al mercado. Los cibercafés proliferaron en todo el país. De esta manera, aquellos que no tenían computadoras o internet en casa podían acceder a la web a un costo de alrededor de USD 0.65 por hora, con un ancho de banda de 512 kbit/s (Tábora, 2007; Comisión de Verdad y Reconciliación 2).

La liberalización del mercado de las telecomunicaciones en la década de 1990 produjo un aumento significativo de operadores de telecomunicaciones, lo cual vendría a ser significativo en la siguiente década, sobre todo, durante la crisis política que trajo el golpe de Estado del 2009.

\section{Primera década del nuevo milenio. Nuevo régimen, medidas populistas y gran diversidad de TIC}

A principios de la década del 2000 se había incubado un descontento generalizado debido al fracaso de las medidas neoliberales en mejorar el nivel de vida. Lo anterior estuvo aunado a la casi total eliminación de la clase media mediante una combinación perversa de medidas como la reducción del empleo público, una política de contención salarial y la devaluación de la moneda. Esto generó las condiciones ideales para que Manuel Zelaya Rosales ganara las elecciones del 2005. Los datos recabados indican que Zelaya fue elegido en un ambiente caracterizado por el desencanto con la política, la alta criminalidad, la desigualdad económica, la impunidad, la pobreza y la violencia relacionada a las pandillas (Cannon y Hume, 2012; Gordon y Webber, 2013, Pérez, 2012).

Su propuesta de gobierno llamada "Plan de Poder Ciudadano" resonó en el electorado porque reveló un giro hacia la izquierda ideológica mediante la adopción de medidas alineadas con el movimiento latinoamericano denominado "Marea Rosa"7 que, aunque se trataba de gobiernos con influencia izquierdista, no eran del todo radicales. La Marea Rosa es, más bien, un espectro de movimientos y organizaciones políticas de centroizquierda, que se distinguen por una variedad de enfoques. Sin embargo, sus miembros comparten algunos rasgos en común: aceptan la democracia y aunque, adoptan y usan el capitalismo en diversos grados, buscan activamente su reforma (Beasley-Murray et al., 2009; Allen, 2008; Webber y Carr, 2013; Remmer, 2012; Tockman, 2009).

El gobierno de Zelaya compartió las características de los gobiernos de marea rosa de varias formas. Llegó al poder a través de elecciones, reunió el apoyo de la sociedad civil, rechazó la hegemonía estadounidense, implementó medidas de bienestar social como el aumento del cincuenta por ciento en el salario mínimo, se unió a los acuerdos comerciales regionales como el ALBA (Alternativa Bolivariana de las Américas) y promovió la reestructuración estatal a través de una encuesta de opinión nacional denominada "Cuarta Urna" para decidir si llevar a cabo o no un referendo para cambiar la constitución (Argueta, Huhn, et al., 2011; Brewer-Carias, 2009; Grandin, 2009; Peetz, 2009; Prevost, et al., 2012; Salomón, 2009, 2010; Taylor-Robinson, 2009). 
A mediados del 2008 la radio seguía siendo la TIC más prevalente seguida del teléfono celular y de la televisión (Figura 1). Según datos oficiales de CONATEL, para mediados del 2008, Honduras tenía un total de 950 estaciones de radio propiedad de 453 operadores. Aunque Emisoras Unidas y Audio video continuaron siendo los mayores operadores con un total de 129 estaciones, existían 822 estaciones "alternativas" en todo el país. Los datos sobre televisión indican que, en 2008, Televicentro era dueño del 24 por ciento de las estaciones. Sin embargo, también había un número significativo de estaciones alternativas en todo el país. Las computadoras y los teléfonos fijos, por el otro lado, eran escasos. Estaban presentes únicamente en el $10 \%$ de los hogares. Solo el $8.5 \%$ de la población eran usuaria de internet (distribuidos entre hogares, empresas, escuelas, universidades y servicios tales como cibercafés y servicios de acceso a la comunidad).

Figura 1

PENETRACIÓN DE TIC EN EL 2008

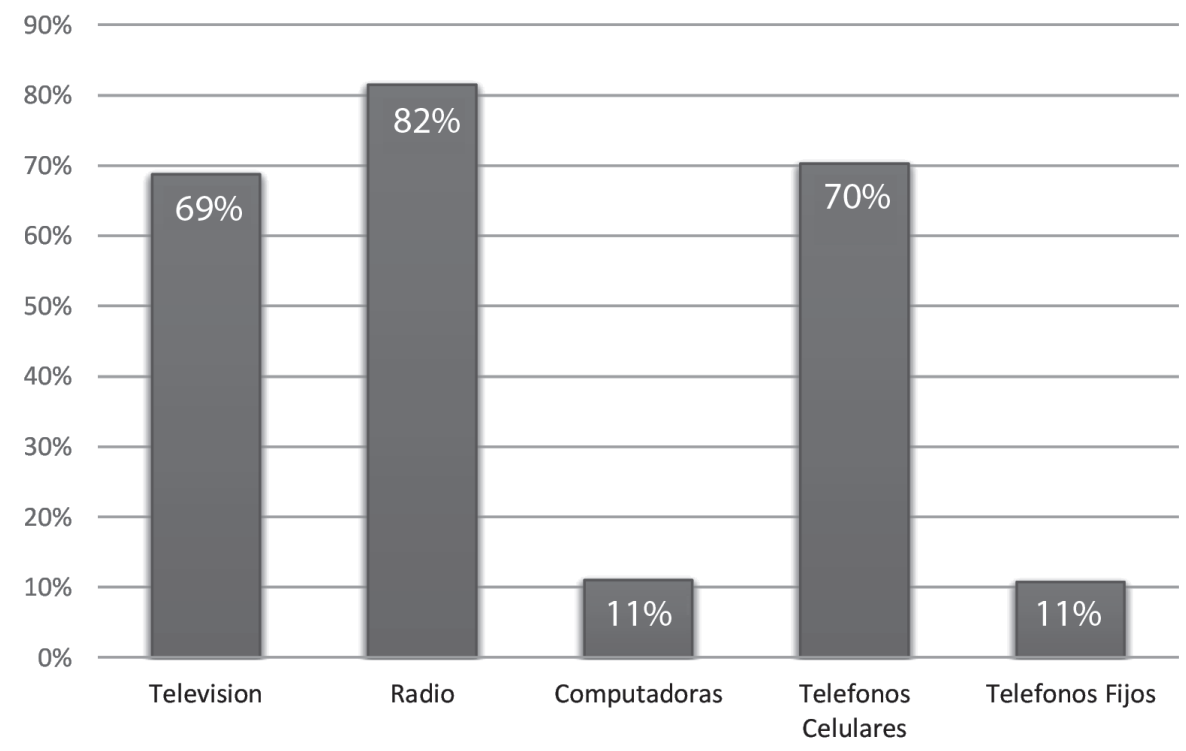

Fuente: CONATEL. ${ }^{8}$

\section{Telefonía celular. Rápida penetración y accesibilidad}

La penetración aumentó consistentemente durante la primera década, por lo que, a finales del año 2008, el 79 por ciento de la población tenía teléfono. Los teléfonos celulares eran más fáciles de obtener que un teléfono convencional y se convirtieron en parte de la vida cotidiana de las personas. Los mensajes de texto se hicieron más populares. 


\section{HONDUTEL y la telefonía fija. Inestabilidad y escándalos}

HONDUTEL, una de las empresas estatales más rentables, ha desempeñado un papel importante en el apoyo a las finanzas del gobierno central. Sin embargo, en el 2005, cuando terminó su período de exclusividad, también había dejado de ser rentable.

Se esperaba que la nueva ley de telecomunicaciones, la cual abriría el mercado de la telefonía fija, estuviera redactada para finales del 2007. A través de la Propuesta de Poder Ciudadano, Zelaya propuso fortalecer HONDUTEL, a través de una estrategia que ampliara su servicio a poblaciones desatendidas y que mejorara su funcionamiento para hacerla más eficiente y competitiva. Si bien la cantidad de teléfonos fijos y celulares aumentó, el impacto de las medidas propuestas por el Poder Ciudadano es difícil de determinar debido a una serie de escándalos de corrupción que ocurrieron durante el gobierno de Zelaya.

En septiembre de 2007, se denunció una extensa red de corrupción dentro de HONDUTEL (Diario La Prensa). Funcionarios fueron acusados de conducir un plan de tráfico gris en el que recibieron sobornos de compañías hondureñas y estadounidenses. En el mismo año se filtraron en YouTube una serie de conversaciones telefónicas entre miembros del gabinete de Zelaya, en las cuales se puede escuchar a funcionarios creando estrategias para controlar los medios e influir en el proceso de la nueva ley de telecomunicaciones para garantizar que HONDUTEL mantuviera la exclusividad de telefonía.

Estos hechos tuvieron un impacto en la visión del electorado acerca del plan del Poder Ciudadano, interfiriendo en la redacción de la nueva ley de Telecomunicaciones y perjudicaron la capacidad operativa de HONDUTEL. A principios de 2008, el número de suscriptores de internet había disminuido y HONDUTEL estaba reportando pérdidas (Comisión de Verdad y Reconciliación). Además, debido a estos escándalos, los medios de comunicación corporativos generaron el rumor que Zelaya intentaba controlar las telecomunicaciones y los medios de comunicación. Este rumor generó preocupación cuando Zelaya puso en marcha la campaña propagandística para promover la iniciativa denominada "Cuarta Urna". La cual consistía en una consulta popular para decidir si se llevaba a cabo o no un referéndum nacional que crearía las bases para la reelección presidencial. Cabe recordar que la reelección presidencial es taxativamente prohibida en la Constitución Política vigente.

\section{Descentralización y polarización de los medios de comunicación. Radio y televisión antes del golpe}

Antes de la liberalización del mercado, la televisión y la radio habían sido tradicionalmente propiedad de un pequeño grupo de empresas. En la década del 2000, la apertura de los mercados representó una oportunidad para periodistas independientes, sindicatos, iglesias y organizaciones de pueblos indígenas para crear sus propias 
estaciones de radio y televisión, sitios web y periódicos en línea. También representó una oportunidad para que los propietarios habituales de medios de comunicación adquirieran más estaciones. El mercado de la radio y la televisión pasó de ser el oligopolio de unas pocas empresas a convertirse en una amplia red de estaciones grandes y pequeñas.

El gobierno de Zelaya aprovechó este doble proceso de crecimiento y descentralización de TIC para promover el Plan de Poder Ciudadano. La Cuarta Urna fue diseminada a través de una intensa campaña propagandística a través de medios impresos, radiales y televisivos. La campaña sugería que la Cuarta Urna era una forma de resolver muchos de los problemas del país. También enfatizó que era el derecho y el deber de todos y todas de participar en el referéndum. En uno de los anuncios de televisión se ve a Zelaya diciendo: "Para preguntarle al pueblo si quiere una nueva constitución, porque lo que está ahorita no nos gusta. Porque hay mucha violencia, mucha pobreza, mucha corrupción, mucha exclusión en este modelo de desarrollo. El pueblo necesita revisar lo que está pasando" (Terco Producciones, 2009).

A partir de mayo de 2007, el presidente Zelaya implementó una programación gubernamental obligatoria en todos los medios. Exigió una cadena nacional de 2 horas en todas las estaciones de radio y televisión para discutir el progreso Plan de poder ciudadano. Organizaciones internacionales, como Freedom House, llamaron la atención sobre estas medidas, las etiquetaron en su informe Freedom of the Press 2008 como control de los medios de comunicación.

Otra medida de difusión fue la adquisición de un canal de televisión denominado la Red de Información de Poder Ciudadano de Honduras (Canal 8), el cual comenzó a funcionar en agosto de 2008. Los informes oficiales sostienen que la frecuencia asignada al Canal $8^{9}$ había sido asignada previamente a un operador privado. También hubo preguntas respecto a la compra de equipos sin el proceso de licitación requerido. La Corte Suprema rechazó la adquisición. Sin embargo, el canal continuó operando.

Además de la nueva infraestructura de difusión, hubo una fuerte inversión en campañas de medios de comunicación para promover las medidas de Poder Ciudadano. Los medios alternativos se convirtieron en un aliado importante que cubría las iniciativas de la Cuarta Urna de una manera más favorable que los medios convencionales. Informantes de este estudio argumentaron que esto se debió a la alineación ideológica de los medios alternativos con Zelaya. Según un informante "Zelaya convirtió a medios de comunicación más pequeños como Cholusat, Radio Progreso y el Canal 36 en sus aliados... contó con su apoyo, porque su discurso se centraba en el desarrollo y estos medios también luchaban por las causas populares... les gustó su discurso sobre el desarrollo y su entrega a la gente" (Internacional 1).

Estas medidas le permitieron a Zelaya reunir el apoyo de numerosos sindicatos. ${ }^{10}$ Estas organizaciones jugaron un papel muy importante en la difusión de los ideales de la Cuarta Urna al prestarle sus recursos a la campaña. Después del golpe de Estado, se convirtieron en actores claves en el Frente Nacional de Resistencia Contra el Golpe. 


\section{Nuevas alternativas de comunicación. El internet antes del golpe de Estado}

La penetración y el acceso al internet se mantuvieron bajos, pero crecieron consistentemente durante la primera década del 2000 . Solo el 8.5 por ciento de la población podía acceder a la web. ${ }^{11}$ La presencia en línea de periódicos, la televisión y la radio también era escasa. Existían solamente algunos blogs, cuentas de YouTube, Twitter y de Facebook. Sin embargo, a pesar del bajo acceso a este medio, los informantes de este estudio aseguraron que las redes sociales se volvieron muy útiles para promover la Cuarta Urna.

Tabla 2

PENETRACIÓN DE INTERNET EN HONDURAS DE 2000 A 2017

\begin{tabular}{rrrcc}
\hline Año & $\begin{array}{c}\text { Suscriptores } \\
\text { fijos y móviles }\end{array}$ & $\begin{array}{c}\text { Usuarios } \\
\text { de internet }\end{array}$ & $\begin{array}{c}\text { Usuarios por cada } \\
\text { 100 habitantes }\end{array}$ & $\begin{array}{c}\text { Tasa de } \\
\text { crecimiento }\end{array}$ \\
\hline 2000 & 11538.60 & 77820.00 & 1.20 & 21.33 \\
2001 & 15044.80 & 94415.80 & 1.42 & 87.72 \\
2002 & 16856.00 & 177242.00 & 2.60 & 88.90 \\
2003 & 18551.00 & 334809.79 & 4.80 & 17.84 \\
2004 & 22227.00 & 394529.63 & 5.60 & 17.22 \\
2005 & 25820.00 & 462484.10 & 6.50 & 23.46 \\
2006 & 45522.00 & 570960.00 & 7.80 & 24.08 \\
2007 & 68855.00 & 708473.49 & 9.40 & 4.43 \\
2008 & 108600.00 & 739863.07 & 9.60 & 23.00 \\
2009 & 207687.53 & 771912.88 & 9.80 & 31.52 \\
2010 & 306389.67 & $949,426.82$ & 11.80 & -0.23 \\
2011 & 405862.60 & 1248727.58 & 15.20 & 18.40 \\
2012 & 759306.80 & 1245840.37 & 15.30 & 31.47 \\
2013 & 1293955.00 & 1475117.68 & 17.80 & 19.84 \\
2014 & 1507727.00 & 1939395.19 & 23.00 & 10.69 \\
2015 & 1649600.00 & 2324240.17 & 27.10 & 29.50 \\
2016 & 2156593.00 & 2572699.00 & Datos no & \\
2017 & 2500398.00 & 2615573.55 & disponibles & \\
\hline & & & & \\
\hline
\end{tabular}

Fuente: CONATEL. ${ }^{12}$

Los activistas entrevistados sugieren que las redes sociales y la mensajería instantánea permitieron complementar el mensaje de los anuncios de radio o televisión 
gracias a la posibilidad que ofrecen los medios sociales para mantener conversaciones. Lo anterior les permitió explicar los objetivos de Cuarta Urna en términos más simples.

Hacia finales de la década, el entorno institucional, social y económico de Honduras era de descontento, de insatisfacción con el entorno político, mayor voluntad de reprimir por parte de las fuerzas sociales conservadoras y una profunda polarización de los alineamientos políticos. Las élites y los militares se alinearon contra el presidente y las organizaciones laborales e indígenas que lo apoyaban.

Sin embargo, la sociedad civil en ambos lados del debate se revitalizó. Especialmente aquellos que estaban a favor de la Cuarta Urna, ya que colaboraron de manera activa y por primera vez con el poder ejecutivo. Los cambios que estaban ocurriendo en las estructuras del país y la participación de organizaciones internacionales en el referéndum les habían llenado de entusiasmo.

Mientras tanto, la oposición se organizó para protestar contra el referéndum y llamar la atención sobre las violaciones a los derechos humanos y el abuso de poder durante el mandato de Zelaya. Después de todo, la Cadena Nacional obligatoria, los escándalos de corrupción en HONDUTEL, la represión de los manifestantes y el ambiente inhóspito para los periodistas de investigación habían sido fuertemente criticados por las organizaciones de derechos humanos locales e internacionales.

Esta fuerte polarización se reflejó y exacerbó tanto en los medios alternativos locales, que apoyaban al gobierno, como en los medios corporativos que rechazaban la Cuarta Urna. Por lo tanto, la sociedad civil, a pesar de la baja penetración de internet, había comenzado a explorar medios alternativos. Algunos habían comenzado sus propios sitios web, blogs, canales de YouTube y páginas de Facebook.

\section{Las TIC durante y después del golpe del 2009}

El 28 de junio, el día en que se había programado el referéndum de la Cuarta Urna, la gente se despertó a la noticia de que el presidente había sido expulsado del país. A las 4 de la mañana miembros del ejército habrían secuestrado a Zelaya a punta de pistola y lo sacaron del país a través de la base aérea estadounidense ubicada en el valle de Comayagua. La consulta nunca se llevó a cabo. Algunos informantes indicaron que durante las siguientes horas fue difícil saber exactamente qué había sucedido, pues la mayoría de los medios de comunicación habían salido del aire y los medios corporativos transmitían películas o música en lugar de su programación habitual. Un activista de la Cuarta Urna explica:

Me levanté a las 4 esa mañana, encendí el televisor en el canal 8, el canal oficial del gobierno. De repente, interrumpieron su programación regular y dijeron que había habido un intento de golpe contra el presidente. Hablaron de cómo las llamadas telefónicas a su casa no estaban pasando y no sabían exactamente lo que estaba sucediendo. Entonces, el canal salió del aire. 
Fue entonces cuando entendi que habia habido un golpe... Saqué toda la propaganda de mi auto (Activista 5).

La gente tuvo que recurrir a sus teléfonos celulares para hablar con otras personas o acceder a internet y darse cuenta de que había habido un golpe de Estado. Un miembro de una prominente organización internacional explica:

Fui una de las primeras personas en enterarme porque alguien cercano al presidente me llamó... Durante las siguientes horas, no supimos cómo proceder. No había electricidad, así que no pudimos ver noticias en la televisión. Mi única fuente de información fue mi teléfono inteligente. Me permitió estar en contacto con todos mis contactos (Internacional 2).

En esa misma mañana, en una Cadena Nacional, el Congreso Nacional anunció que Zelaya había renunciado oficialmente a la presidencia y presentó una carta con la firma falsificada de Zelaya. Luego, el presidente del Congreso, Roberto Micheletti, ${ }^{13}$ fue juramentado como presidente interino de la República e inmediatamente reemplazó a todos los miembros del gabinete que objetaron el golpe de Estado.

\section{Se exacerba la severa polarización de radio y televisión}

Los medios de comunicación, los cuales desde mucho antes se habían polarizado, mostraban diferentes versiones de los hechos. Quienes denunciaban el golpe de Estado fueron severamente reprimidos, como lo explica un activista:

Los medios de comunicación más grandes en Honduras son los golpistas... Influyeron en la opinión de las personas a favor del golpe. Pero también tenemos estaciones de radio independientes... y una gran red de radios comunitarias en todo el país, quienes rechazaron el golpe. Estas radios divulgaron lo que realmente estaba sucediendo. Las autoridades y la policía cerraron inmediatamente estas estaciones. Todo su equipo fue destruido o desmantelado (Activista 1).

A la gente se le dificultó formarse una opinión acerca de la legalidad del golpe y decidir su postura sobre los eventos. Al tratar de encontrar información sobre la legalidad del golpe y las acciones del gobierno de facto, descubrieron que los canales tradicionales no eran confiables, ya que solo mostraban una versión de la historia. Por lo tanto, comenzaron a buscar activamente TIC alternativas. Cambiaron sus hábitos de comunicación y usaron otras fuentes. Los indicadores de las TIC y los testimonios recopilados indican que en ese momento Televicentro, Emisoras Unidas y Audio Video eran los operadores de televisión y radio más populares. Sin embargo, después de conocer su postura con respecto al golpe, la gente comenzó a cambiarse a estaciones alternativas: 
Asi es que cuando la gente vio su comportamiento cínico ocultando la verdad, y aprendieron que ocultar la verdad causa la muerte, los rechazaron y comenzaron a buscar otros medios. Hubo entonces un rechazo generalizado del control de la prensa y la falta de libertad de prensa. Se dieron cuenta por primera vez que, al elegir una fuente de información, es muy importante considerar la forma en que se maneja la información... Fue extraordinario. La gente cambió el dial y dejó de escuchar Radio América y HRN. En cambio, sintonizaron una pequeña estación de radio, Radio Globo, la que rechazó el golpe y le dio cobertura a las protestas. Era la estación con más cobertura en Tegucigalpa. En San Pedro Sula y la región de Cortés, estaba Radio Progreso. A través del país pudimos encontrar pequeñas estaciones de radio locales que comenzaron también a generar ruido (Sociedad Civil 1).

\section{El internet. Una herramienta para hacer aliados, colaborar, obtener ayuda, documentar y denunciar}

Muchas de las estaciones nacionales de radio y televisión comenzaron a transmitir por primera vez a través del internet. Los ciudadanos comenzaron a usarlo como una herramienta con más posibilidades. Esto le permitió a la gente, los medios de comunicación y las organizaciones trascender fronteras y hacer denuncias, obtener ayuda internacional, hacer aliados, colaborar y documentar los hechos. Los informantes de este estudio se dieron cuenta de que, debido a la crisis de medios, en lugar de obtener información era más importante proporcionarla para llamar la atención del mundo sobre lo que sucedía en Honduras.

Los periodistas y activistas independientes se percataron de que "el mundo lee en línea, y dada la baja penetración de internet en Honduras, los sitios web no tendrían un impacto inmediato dentro del país, pero tendrían un gran efecto multiplicador en el resto del mundo" (Medios 2). Por lo tanto, usaron sus sitios web y blogs para mostrar lo que el gobierno de facto no quería que se viera. Un periodista independiente lo ilustra de la siguiente manera: "recibimos tantos comentarios en nuestro sitio web. Una historia obtuvo 60 mil comentarios. Algunas de nuestras historias llegaron a más de un millón de comentarios" (Medios 2).

Descubrieron que sus blogs y sitios web podrían usarse para contrarrestar las declaraciones del gobierno de facto y proporcionar su propio análisis del golpe. Muchos blogueros reutilizaron sus bitácoras digitales, generalmente dedicadas a pasatiempos, para cubrir el golpe. Los periodistas ayudaron a refutar los rumores establecidos por el gobierno de facto, como el que decía que el referéndum llamado Cuarta Urna era realmente una consulta para aprobar la Asamblea Nacional Constituyente. Tomaron fotos de las papeletas y las subieron a sus blogs para mostrar que la papeleta en realidad preguntaba si se debía realizar una consulta para cambiar la Constitución Política y no convocaba a una Asamblea Constituyente como lo indicaba el gobierno de facto. 
Los datos proporcionan evidencias de una fuerte represión gubernamental. Los informantes argumentan que, si bien es cierto que los medios de comunicación no les dieron cobertura a los actos de represión, los miembros de la resistencia los denunciaron ampliamente a través de medios alternativos y del internet. Se volvieron muy eficaces en documentar y diseminar informes de violencia, contrarrestar los ataques del gobierno de facto y compartir recursos para mejorar su cobertura. Existen numerosos relatos, videos y fotos de manifestantes, activistas y periodistas golpeados, capturados y asesinados. También hay reportes de bombas lacrimógenas, acoso, violaciones y secuestros. Estas denuncias ayudaron a resaltar las violaciones de los derechos humanos del régimen a nivel local e internacional. Como subrayó un activista:

Las nuevas TIC facilitan la divulgación de información en Honduras y en el resto del mundo. La respuesta fue generalmente inmediata. Una vez que las organizaciones internacionales escucharon que se realizó un asesinato político, publicaron sus declaraciones de reacción y las enviaron al gobierno para presionarlas a que dejen de cometer estos abusos. Ahora tenemos esta ventaja que antes no teníamos. Cuando fui detenido, los miembros de las ONG de derechos humanos respondieron en menos de quince minutos... En la década de los ochentas, yo era miembro de una organización estudiantil. Entonces, no teníamos acceso a los medios alternativos para denunciar el abuso policial o militar, ni teníamos teléfonos celulares... Si hubiéramos tenido esta tecnología en los años ochentas, habría habido menos asesinatos extrajudiciales (Activista 1).

También pudieron objetar la oposición usando datos y cifras. Por ejemplo, sacaron a la luz a través de las redes sociales y correo electrónico un recorte de periódico de 1993, donde se muestra al actual jefe de las Fuerzas Armadas y perpetrador del golpe, el General Vásquez Velásquez, capturado por la policía por haber estado involucrado con una banda de contrabando de automóviles.

Los activistas, por medio de los medios sociales, crearon conciencia sobre las alianzas entre las élites y los medios de comunicación corporativos, así como sobre el control y la manipulación de la información. Un evento fundamental fue la muerte de Isis Obed Murillo el 4 de julio. Isis era un joven manifestante que fue asesinado durante el primer intento de retorno que Zelaya hizo a Honduras. Los militares dispararon contra miles de manifestantes que esperaban afuera del aeropuerto nacional. Una de las balas impactó al joven y lo mató. Los activistas denunciaron la manipulación que se hizo de la fotografía de Isis para evitar mostrar su cuerpo ensangrentado.

Los datos disponibles indican que la red de apoyo de la resistencia al golpe creció muy rápidamente gracias al uso del internet. Organizaciones que nunca habían colaborado previamente, se convirtieron en aliados importantes. Muchas de estas organizaciones eran influyentes y pusieron sus recursos ${ }^{14}$ organizacionales al servicio del movimiento de resistencia. Como subrayó un activista: "El dueño de una pequeña 
estación de radio local le dio a la resistencia un espacio de tiempo, transmitió todas las declaraciones oficiales del movimiento y cubrió todos los eventos" (Activista 7).

Los participantes en este movimiento argumentaron que las TIC les permitieron colaborar más fácilmente, construir redes sociales y fortalecer sus vínculos: "A través de internet, pude hacer contactos con organizaciones internacionales. La organización de derechos humanos con la que colaboro utiliza el internet en gran medida para aumentar su red de alcance" (Activista 7).

El movimiento de resistencia creó redes transnacionales de movilización nunca vistas. Un dirigente de una organización miembro del Frente Nacional de Resistencia señaló:

El golpe ha despertado muchos sentimientos entre varias organizaciones. Mi organización trabajada con COFADEH, COHDEH, CIPRODEH, CRPT y otras entidades dedicadas a la defensa de los derechos humanos. Además, hemos trabajado con organizaciones feministas como CDM, Visitación Padilla. Antes del golpe, estas organizaciones feministas solo trabajarían en torno a los derechos de las mujeres. Después del golpe, ampliaron su área de enfoque y realizaron estudios sobre los ataques contra las mujeres durante y después del golpe. Lo mismo ha sucedido con organizaciones LGBT, que nunca habian participado en este tipo de movilización. Ahora, gracias a las comunicaciones y la información, han tomado conciencia y están participando activamente contra el golpe con el Frente Nacional de Resistencia Popular (Activista 1).

De esta manera, sindicatos locales e internacionales, medios de comunicación, ONG, activistas y ciudadanos colaboraron para luchar contra el golpe y la represión.

\section{Pidiendo ayuda y denunciando la represión. Uso de la telefonía celular durante el golpe}

Los informantes comenzaron a utilizar los teléfonos celulares para luchar contra la represión, evitar ser detenidos ilegalmente o incluso asesinados. Enfatizaron sobre el poder de los mensajes de texto y la radio para transmitir información rápidamente. Como ilustra una activista:

Fui detenida por la policía por protestar, me metieron en la cárcel sin seguir el protocolo apropiado, asi que temí por mi vida ya que nunca me registraron oficialmente. Afortunadamente, no me quitaron mi teléfono celular, así que llamé y envié un mensaje de texto a una ONG de derechos humanos. Me ayudaron a liberarme... Estoy seguro de que, si no hubiera tenido conmigo mi teléfono celular, no estaría aquí. En cierto modo, un mensaje de texto me salvó la vida (Activista 7).

Esta táctica se hizo tan efectiva que los abogados y periodistas publicaron sus números de teléfono celular en la radio o sitios web para que fuera más fácil para gente 
obtener ayuda. Lo anterior causó una ola de informes ciudadanos. El director de un medio de noticias alternativo explicó que:

Me enviaron mensajes que decían: "En este momento la policía está tomando medidas enérgicas contra los habitantes del barrio X." ¡Y bam!, yo lo cargaba en la web. También enviaban mensajes de Facebook diciendo: "En el vecindario Y la policia está golpeando a las mujeres' o "arrojaron gases lacrimógenos a los estudiantes en sus aulas". La gente se convirtió en nuestros reporteros. De cierta manera, tuve miles de corresponsales (Medios 2).

\section{Respuesta del Estado. Represión y control de la información}

Dado que las estrategias de comunicación y divulgación del Frente Nacional de Resistencia fueron efectivas y hubo tantos medios alternativos diseminando información, el gobierno de facto implementó varias tácticas de represión. Una de las primeras medidas fue nombrar al general Romeo Vásquez Velázquez como gerente general de HONDUTEL, lo cual le devolvió el poder sobre HONDUTEL a las Fuerzas Armadas.

El hostigamiento y la persecución se manifestaron en la militarización de estaciones de radio y televisión alternativas, el decomiso y destrucción de sus equipos y el corte regular de energía eléctrica. Como señaló un activista: “durante el golpe, las estaciones de radio comunitarias fueron las más castigadas. Por ejemplo, la radio Garífuna fue destruida, también lo hicieron con la Voz de Zacate Grande. La Voz Lenca no fue militarizada, pero le bloquearon su señal" (Activista 7).

El gobierno de facto incluso tomó medidas para legalizar tal persecución a través del estado de sitio declarado el 26 de septiembre, mediante el cual suspendieron las garantías civiles por 45 días. El régimen utilizó esta medida restrictiva como una estratagema para clausurar, interrumpir transmisiones y confiscar equipos de TIC opositoras. Los informes de las organizaciones de Derechos Humanos, los testimonios de los informantes y los blogs indican que solo las estaciones que condenaron el golpe de Estado fueron blanco de estos abusos. La nueva ley establecía que:

Está prohibido: cualquier transmisión o publicación hablada, escrita o televisada que ofenda la dignidad humana, funcionarios públicos o atentado contra la ley, resoluciones del gobierno, o de alguna manera amenace la paz y el orden público; CONATEL a través de la Policía Nacional y las Fuerzas Armadas, está autorizado a suspender cualquier estación de radio, estación de televisión o sistema de cable que no se ajuste a su programación a estas disposiciones (Diario Oficial La Gaceta, 2009).

CONATEL ordenó el decomiso de equipo de varias estaciones de radio. Miembros del ejército, la policía y técnicos de CONATEL participaron en el desmantelamiento de estas. Periodistas hondureños e internacionales fueron hostigados de diversas 
maneras. Se les confiscaron sus equipos, fueron amenazados de muerte, despedidos injustificadamente, torturados, secuestrados y asesinados. Se repitieron casos como el siguiente:

El régimen atacó brutalmente a Julio Umaña, un fotógrafo de Diario Tiempo. Después de golpearlo con bastones, los captores uniformados lo detuvieron y le confiscaron su cámara. Fue liberado después de una hora. Le devolvieron su cámara con el chip vacío, sin las imágenes que muestran el salvajismo perpetrado contra miles de ciudadanos que demandan el regreso de Manuel Zelaya Rosales (Rivera, 2009).

Los informantes argumentan que el gobierno de facto se convirtió en "la amenaza número uno para los medios de comunicación alternativos" (Activista 5). Sin embargo, las compañías de teléfonos celulares no fueron intervenidas por los militares durante el golpe de Estado. De hecho, los informantes insisten en que estas se confabularon con el gobierno de facto y apoyaron el golpe. Argumentan que, si bien los teléfonos celulares eran instrumentos muy útiles para combatir la represión, también se usaron contra los miembros del movimiento de resistencia.

Tenemos tres grandes empresas: TIGO, CLARO Y DIGICEL. Todos apoyaron el golpe, algunos más que otros. Los que tenian menos clientes, no eran tan francos en su apoyo al golpe. La más grande, TIGO, fue muy clara acerca de su posición. De hecho, mucha de nuestra comunicación fue interceptada por ellos. Pero, por otro lado, los servicios de telefonía celular se han utilizado contra el movimiento de resistencia. Ellos (el gobierno) querían cortar el servicio, pero eso significaría una gran pérdida monetaria para la empresa, perderían millones y el gobierno no podría persuadirlos de cancelar el servicio (Activista 1).

Los activistas informan que perdían la señal del celular durante las manifestaciones y que el ejército y la policía les tomaban fotografías. Muchos activistas sugieren que fueron víctimas de vigilancia, argumentan que sus teléfonos celulares se comportaron de manera extraña después de que se unieron al movimiento de resistencia. Numerosos activistas también fueron hostigados constantemente por teléfono y recibieron amenazas de muerte y de violación.

Debido a su naturaleza descentralizada, el internet fue una herramienta muy útil para contrarrestar la represión y luchar contra el golpe de Estado (Espinoza-Vasquez, 2015). A pesar de las medidas de represión por parte del gobierno de facto, las estaciones de radio y televisión que fueron cerradas pudieron continuar transmitiendo a través del internet. “Todo el equipo de Radio Globo y Radio Progreso fue destruido, de la misma manera, se desmanteló el Canal 36. Sin embargo, podían transmitir noticias a través de internet" (Activista 1). Algunos medios de comunicación opositores 
reconfiguraron sus equipos y pasaron de depender únicamente de la tecnología de transmisión analógica a un híbrido análogo digital internacional.

Gracias a las nuevas tecnologias como el Internet, las emisoras de radio cuyas antenas habian sido desmanteladas por el gobierno, pudieron transmitir a través de Internet. La información que Radio Globo emitió aqui en Tegucigalpa fue retransmitida nuevamente en El Progreso por Radio Uno. Repetidores de radio e Internet podríamos llegar incluso a las zonas más remotas de Honduras (Activista 1).

De esta forma, las radios comunitarias en Honduras se conectaron entre sí y con otras radios en América Latina. Obtuvieron la señal de internet y la retransmitieron a través de ondas de radio y viceversa. Como subrayó un activista: "163 radios comunitarias en América del Sur transmitieron noticias sobre el golpe de Estado hondureño. Recibieron una señal de internet y la transmitieron por ondas de radio" (Activista 1). De la misma manera, los activistas recurrieron a nuevas estrategias para eludir la vigilancia en las redes sociales. Abrieron cuentas alternativas de correo electrónico y de Facebook y adquirieron varios teléfonos celulares o tarjetas SIM ${ }^{15}$ para contrarrestar la vigilancia por las redes sociales.

Aquellos de nosotros que pensábamos que nuestros teléfonos habian sido intervenidos, a veces tomamos algunas medidas preventivas. Sin embargo, no fue de manera organizada. Tengo dos teléfonos celulares con cuatro números de teléfono diferentes. Solo uno de esos números está a mi nombre. Los otros están bajo los nombres de personas que no tienen nada que ver con la resistencia. Esta no es una medida duradera, pero ayuda temporalmente a desviar el llamado telefónico de la policía (Activista 1).

\section{El regreso al Modelo Neoliberal y el aumento de la protesta social: Las TIC después del golpe de Estado}

La primera parte de la crisis causada por el golpe de Estado de junio del 2009 culminó con las elecciones que se llevan a cabo en noviembre del mismo año, a pesar de las múltiples protestas. Porfirio Lobo del Partido Nacional fue juramentado como presidente el 27 de enero de 2010, al tiempo que el movimiento de resistencia "reiteró su decisión de ignorar este régimen, por considerando la continuación de la dictadura impuesta por la oligarquía durante el golpe del 28 de junio". ${ }^{16}$

El Frente de Resistencia Popular calificó al diálogo propuesto como una "farsa" y a su plan de gobierno una forma de "validación de la dictadura de la oligarquía a nivel nacional e internacional, y un método para asegurar la continuación de un sistema que margina y explota a los sectores populares para garantizar los privilegios deudos pocos" (Comunicado N. 34, Frente Nacional de Resistencia Contra el Golpe de Estado, 8 de noviembre, 2009). 
El gobierno de Lobo se caracterizó por el retorno al modelo neoliberal, el cual aprueba leyes que favorecen la ampliación de mercado y la inversión nacional y extranjera (Sosa, 2014; 2015), incluso iniciativas como las fallidas ciudades modelos. A pesar de comenzar un dialogo de reconciliación nacional, durante el gobierno de Lobo se exacerbó la crisis de derechos humanos debido al asesinato de activistas y periodistas (Human Rights Watch). Lo anterior puso en duda la democracia hondureña y la capacidad de sus gobernantes de resolver los problemas de la pobreza, corrupción y el crimen (Ruhl, 2010).

Uno de los resultados de la movilización de la sociedad civil durante el gobierno de Lobo fue la realización de elecciones generales, las cuales ganó Juan Orlando Hernández del partido oficialista, primero en el 2013 (Sánchez, 2016; Sosa, 2014; Carasik et al., 2013) y de nuevo en una reelección inconstitucional en el año 2017. Ambas elecciones tienen múltiples denuncias de fraude por parte de la sociedad civil y las organizaciones internacionales. Además del fraude, su victoria se atribuye a la vieja institucionalidad que predomina en Honduras (Sosa, 2014; 2015). Durante el gobierno de Hernández se llevan a cabo nuevas movilizaciones sociales, como la marcha de las antorchas, en protesta a los múltiples escándalos de corrupción; y las protestas al fraude electoral del 2017. Se ha destacado también que debido a la situación delictiva y de violación frecuente de los derechos humanos ${ }^{17}$ se produjeron las crisis migratorias de menores no acompañados y familias en la frontera de EE. UU., en el 2014 y en el 2018.

Las organizaciones de la sociedad civil han desempeñado un papel importante movilizando personas e información durante esta década (Portillo, 2016). Tanto la sociedad civil como el Estado adoptaron formas más estratégicas de usar las TIC para organizarse, movilizar gente e información. El gobierno las usó para apoyar sus iniciativas, mientras que la sociedad civil, las utiliza para colaborar y establecer nuevas alianzas. Durante el gobierno de Porfirio Lobo, CONATEL dejó de publicar las estadísticas oficiales de telecomunicaciones; por eso no se cuenta con datos oficiales desde el 2012. Para este estudio, se intentó obtener esta información en numerosas ocasiones y por diferentes medios, incluyendo el portal de transparencia del gobierno de Honduras y CONATEL. No hubo ninguna respuesta. Sin embargo, el resto de la información recabada para este estudio indica que las prácticas de uso de las TIC adoptadas por la sociedad civil tuvieron un impacto en la a nivel macro en el país.

\section{Teléfonos celulares y mensajería de texto posgolpe. Herramientas para diseminar información y para vigilar}

La penetración del celular subió después del golpe de Estado. Las compañías de teléfonos celulares vieron un crecimiento en las ventas de teléfonos celulares y el numero líneas de teléfonos celulares aumentó durante la crisis del golpe del 2009. Entre julio de 2009 y enero de 2010 hubo más teléfonos que personas (Tabla 1). 
En esta década los teléfonos celulares se convirtieron en un portal para obtener información, pero sobre todo en una herramienta para diseminar información sobre movilizaciones, discutir sobre política y para denunciar la represión. Los mensajes de texto, en particular, se usan ampliamente para estos fines. Activistas y miembros de la sociedad civil envían y reenvían mensajes a sus listas de contactos o a sus grupos de WhatsApp.

Durante el golpe el Estado intentó controlar las telecomunicaciones al solicitar a las compañías de telefonía celular que suspendieran el servicio. Como señaló un activista:

A pesar de que las compañias de telefonía celular apoyaron el golpe, y cortaron la señal de los teléfonos celulares durante largos períodos de tiempo, la gente usaba sus teléfonos celulares para transmitir noticias. Cada vez que recibía un mensaje de texto, lo reenviaba a gente que conocía. Los textos causarían una reacción en cadena (Activista 2).

Esta medida no duró mucho tiempo porque significó pérdidas económicas para las compañías celulares que colaboraran con el gobierno. Los miembros de la oposición temen que desde entonces las compañías celulares estén colaborando con el Estado para monitorear sus conversaciones y mensajes de texto. Algunos activistas nos informaron que sus teléfonos celulares tienen un comportamiento "extraño", mencionan que pueden escuchar ecos o que una tercera persona está escuchando. Consideran que la comunicación a través de teléfonos celulares, teléfonos o correo electrónico, es insegura. De hecho, asumen que siempre están siendo escuchados y por eso los asuntos importantes solo los discuten cara a cara. Sin embargo, los teléfonos celulares siguen jugando un papel crucial para ayudar a la sociedad civil a organizarse, obtener y diseminar información.

\section{Aumento del control estatal sobre la radio y televisión alternativa}

La radio continúa siendo muy popular en Honduras y sigue teniendo un papel determinante. Algunos informantes argumentaron que, si bien siempre hay una nube de desinformación y silencio en las radios corporativas, las radios comunitarias discuten abiertamente los eventos y abren sus micrófonos para permitirles a la población en general compartir sus experiencias e informar sobre incidentes. También argumentan que en muchos casos la radio les ha salvado la vida, ya que la gente denuncia por la radio cuando hay arrestos y capturas ilegales por parte de la policía. Esto alerta a abogados y defensores de los derechos humanos. Además, las radios alternativas cubren noticias sobre manifestaciones, la brutalidad policial y militar y entrevistan a los actores políticos que son ignorados por los medios de comunicación corporativos. 
$\mathrm{Al}$ igual que la radio, la televisión estaba polarizada desde antes del golpe de Estado. Sin embargo, después del golpe las personas se cambiaron a canales independientes más pequeños porque no se satisfacían sus necesidades de información. Medios alternativos como Canal 36 y TV Globo vieron un enorme crecimiento en popularidad desde el golpe de Estado. Dado el rol tan importante de la red de radios y televisoras alternativas, durante el golpe el Estado intentó regularlas haciendo uso de una ley "para mantener la paz y el orden público".

En realidad, esta legislación pretende frenar el surgimiento de medios alternativos. Primero, en diciembre de 2009, se cambiaron las reglas para la asignación de frecuencia ${ }_{1}^{18}$ a fin de dificultar la adquisición de una licencia para radio o televisión. Luego, en 2010 y 2011, suspendieron nuevas solicitudes de licencias de canales de televisión. ${ }^{19}$ Finalmente, en agosto de 2011, se suspendieron los permisos para nuevas estaciones FM entre 88-108 MHz. ${ }^{20}$ CONATEL señala que no ha resuelto peticiones de nuevas frecuencias porque el espectro radioeléctrico está saturado. No obstante, esta saturación sucede principalmente en las zonas más pobladas del país, no en zona remotas. La medida ha evitado que se abran nuevas emisoras de radio análogas; sin embargo, muchas estaciones transmiten a través del internet.

\section{Amplia adopción de internet, redes sociales y correo electrónico}

Al final de la década, la tasa anual de usuarios de internet aumentó significativamente. El año anterior al golpe de Estado, la tasa de crecimiento pasó del $25 \%$ al $55 \%$. Durante la crisis del golpe, el número de usuarios y suscriptores pasó de 658000 a 892 000. Este crecimiento puede explicarse por la adopción de fuentes alternativas de información. "El internet desempeñó un papel fundamental. Durante el golpe de Estado, el tráfico de nuestro sitio web aumentó de 25 mil personas a 80 millones" (Medios 2).

Sin embargo, el número de proveedores de servicios de internet disminuyó en el 2009. Esta baja se debe a las medidas del gobierno de facto para reprimir el flujo de información. Aunque el acceso al internet todavía está limitado a las zonas densamente pobladas y aquellos con más poder adquisitivo, las organizaciones de sociedad civil y los ciudadanos en general, usan las redes sociales (Facebook, Twitter, blogs y YouTube) como plataforma para reportar violaciones de derechos humanos a partir de sus propios videos o fotos, con lo cual asumen el rol de "reporteros".

La confianza en el internet como la fuente de divulgación de la verdad, más el crecimiento de usuarios de las redes sociales como Facebook, WhatsApp y Twitter en la última década significó el uso amplio de estas plataformas por parte de candidatos a la presidencia y por los políticos en general. Esto ha facilitado la comunicación entre candidatos y votantes, pero también la propaganda y la persecución.

La presencia en línea del partido político del Frente Nacional de Resistencia (Partido LIBRE) fue consistentemente utilizada para apoyar sus campañas, así como 
para educar sobre la denuncia de irregularidades en las elecciones. De esta manera, coordinaron sus sitios web, blogs, perfiles de Facebook, cuentas de Twitter. Lo anterior fue el producto de un esfuerzo conjunto de los miembros individuales y organizacionales del movimiento.

Durante las elecciones del 2013 y el 2017 se usaron las redes sociales para monitorear la validez de las encuestas y publicar irregularidades. La polarización de los medios continuó. Los principales medios de comunicación apoyaron a los candidatos de los dos partidos tradicionales y los medios alternativos respaldaron el partido LIBRE en el 2013 y a la Alianza Contra la Dictadura en el 2017. Mientras los medios convencionales reportaron elecciones transparentes, los medios alternativos informaron sobre las irregularidades cometidas.

El actual presidente, Juan Orlando Hernández, tiene una presencia de internet y de medios más sofisticada de lo que tuvo Zelaya en su momento. El canal de televisión estatal, Televisión Nacional de Honduras, ${ }^{21}$ es una plataforma multimedia que presenta programación comercial mezclada con propaganda y promoción de la llamada "Marca País Honduras", la cual es una alianza con el sector privado, las corporaciones de telecomunicaciones, Televicentro y Emisoras Unidas para promover el turismo.

Los activistas reconocen que, si bien las TIC son cruciales para su causa, estas tecnologías también son utilizadas en su contra. El Estado hondureño adoptó tácticas de represión más sofisticadas basadas en las TIC. Los medios alternativos y la sociedad civil informaron de ataques cibernéticos a sus sitios web y la vigilancia a sus correos electrónicos. Facebook se convirtió en una ventana a la vida personal de los activistas, lo cual se utilizó para acosarlos. Temen que "las fotos o la información que subimos puedan ser utilizadas por la policía para rastrearnos" (Activista 1).

\section{Conclusiones}

Se concluye que las TIC por sí solas no determinan la calidad de la democracia en Honduras. Antes bien, se trata de una combinación entre las condiciones del entorno político y las características de la infraestructura de las TIC, las cuales influyen en la capacidad que tienen los ciudadanos de participar en la política. Por un lado, las disposiciones institucionalizadas en el entorno político ${ }^{22}$ pueden facilitar o impedir la expresión y participación política y determinar la configuración de las TIC. Por otro lado, las características como centralización y control de las TIC también pueden influir en la expresión y participación política.

En el caso de Honduras, se pueden observar diferentes combinaciones de configuración de TIC con el sistema político. Un sistema institucional cerrado con TIC altamente centralizadas, como el que tuvo Honduras hasta los años ochenta, dificulta la diseminación de ideas, el diálogo y la participación ciudadana en procesos democráticos y de toma de decisiones. 
Las políticas de liberalización del mercado de los años noventa permitieron la proliferación de muchas estaciones alternativas, acceso al internet y la entrada de compañías celulares, con lo cual se crea una extensa red de comunicación, con más opciones para los ciudadanos. La sociedad civil aprendió a usar esta red de forma estratégica para movilizarse de manera efectiva, pero su participación se vio limitada por la falta de mecanismos institucionales para incluir las voces de la sociedad civil en la toma de decisiones.

Por su parte, aunque un sistema político se intente abrir a través de iniciativas de participación ciudadana, no va a tener efecto si se implementan medidas de control de TIC, aun cuando se cuente con el apoyo de parte de la sociedad civil y de parte de los medios alternativos, como durante el gobierno de Zelaya.

Cuando un sistema político se cierra a la democracia a través de golpes de Estado y de fraudes electorales, la descentralización y la proliferación de las TIC en red pueden ser una herramienta poderosa para promover cambios en las alianzas políticas, luchar contra la represión estatal, divulgar las violaciones de los derechos humanos y crear sistemas alternativos de participación política. Estos sistemas cerrados y autoritarios generan nuevas formas de utilizar las TIC.

La disponibilidad y maleabilidad de las TIC como canales para la difusión de información pueden ayudar o dificultar la movilización de recursos, personas e ideas. A medida que las TIC se vuelven integrales en la sociedad hondureña, también se vuelven una parte esencial de la estrategia contenciosa de la sociedad civil. Estas proveen la capacidad de fomentar nuevas formas de organización para auspiciar la colaboración entre las organizaciones de sociedad civil. Aunque las TIC tienen propiedades específicas para las cuales fueron diseñadas, la gente es capaz de cambiar dichas propiedades de acuerdo con las circunstancias.

En Honduras, la sociedad civil utiliza una variedad de TIC que van desde la radio comunitaria, la televisión, los medios impresos, los dispositivos móviles y las tecnologías basadas en internet. Debido a que hay represión y dificultad de acceso a los medios masivos corporativos, la gente improvisa tanto en la forma en que se usan las plataformas de medios de comunicación e información, como en la forma en que estas plataformas se combinaron y se reestructuraron para diseminar información y colaborar. Sin embargo, a medida que las personas adoptan nuevas TIC, el gobierno, el ejército y la policía también encontraron nuevas formas de controlar la información y de reprimir.

\section{Notas}

1 Los golpes de Estado se llevaron acabo durante los siguientes gobiernos: Julio Lozano Díaz, derrocado en 1957; Ramón Villeda Morales, derrocado en 1963; Oswaldo López Arellano, derrocado en 1972; Juan Alberto Melgar Castro, derrocado en 1978; y Manuel Zelaya Rosales, derrocado en 2009. 
Las dictaduras y gobiernos militares incluyen las de Francisco Bertrand Barahona, 1912-1919; Rafael Salvador Gutiérrez, 1919-1921; Tiburcio Carias Andino, 1933-1949; Julio Lozano Díaz, 1954-1956; Oswaldo López Arellano, 1963-1975; Juan Alberto Melgar Castro, 1975-1978; Junta Militar, 1978-1980; Policarpo Paz García, 1980-1982; y Roberto Michelleti, 2009-2010.

Durante el gobierno de Vicente Mejía Colindres (1929-1933).

Durante el gobierno de Rafael López Gutiérrez (1920-1924).

Durante el gobierno del liberal Ramón Villeda Morales (1957-1963).

Durante el gobierno militar de Juan Alberto Melgar Castro (1975-1978).

Se consideran parte de la Marea Rosa los gobiernos de Luis Ignacio Lula da Silva (2003-2011), Hugo Chávez (1999-2013), Evo Morales (2006-), Rafael Correa (2007-2017), Néstor Kirchner (2003-2007), Cristina Kirchner (2007-2015), Michelle Bachelet (2006-2010, 2014-2018) y Daniel Ortega (1985-1990; 2007-).

A la fecha de publicación de este estudio el ente regulador no ha publicado datos sobre radio y televisión. Se intentó obtener esta información en numerosas ocasiones y por diferentes medios, incluso por medio del portal de transparencia del gobierno de Honduras y CONATEL. No hubo ninguna respuesta.

El Canal 8 fue asignado a la frecuencia 180 a 186 MHZ.

Artistas, profesores, sindicatos, listar indígenas y COPINH.

Distribuida entre hogares, empresas, escuelas, universidades y servicios como cibercafés y servicios de acceso a la comunidad.

A la fecha de publicación de este estudio el ente regulador no ha publicado datos actualizados desde el 2012. Se intentó obtener esta información en numerosas ocasiones y por diferentes medios, incluso por medio del portal de transparencia del gobierno de Honduras y CONATEL. No hubo ninguna respuesta.

Miembro del Partido Liberal.

Recurso organizacional se refiere a recurso humano y tecnológico, por ejemplo, listas de correo, correos electrónicos, teléfonos celulares, sitios web, radios, blogs y páginas de Facebook.

La tarjeta SIM es una tarjeta inteligente dentro de un teléfono móvil, con un número de identificación exclusivo del propietario, la cual almacena datos personales y evita la operación si se elimina, con esta se puede identificar el abonado.

Frente Nacional de Resistencia Popular, Comunicado N. ${ }^{\circ} 46$.

World Report 2018: Honduras.

Comisión Nacional de Telecomunicaciones resoluciones NR13/09 y NR14/09.

Comisión Nacional de Telecomunicaciones resoluciones NR07/10 y NR08/10.

Comisión Nacional de Telecomunicaciones resolucion NR03/11. 
TNH Canal 8 es el mismo que el presidente Zelaya fundó como canal oficial durante su presidencia. Frecuencia 180 a $186 \mathrm{MHZ}$.

Por ejemplo, leyes que regulan: procesos de elecciones, campañas, partidos políticos, asambleas públicas y telecomunicaciones, entre otros.

\section{Bibliografía}

Aalto-Matturi, Sari. “The Internet: The new workers' hall the Internet and new opportunities for the Finnish Trade Union Movement". WorkingUSA 8.4 (2005): 469-481.

Allen, Benjamin S. "Pink tide rising". Berkeley Review of Latin American Studies (2008): 1-3.

Almeida, Paul y Allen Cordero Ulate, eds. Handbook of social movements across Latin america. New York London: Springer Dordrecht Heidelberg, 2015.

Argueta, Otto et al. "Blocked democracies in central america". GIGA Focus Lateinamerika. 8.5 (2011): 8.

Beasley-Murray, Jon, Maxwell A. Cameron y Eric Hershberg. "Latin America's left turns: an introduction". Third World Quarterly 30.2 (2009): 319-330.

Benford, Robert D. y David A. Snow. "Framing processes and social movements: An overview and assessment". Annual review of sociology 26.1 (2000): 611-639.

Bennett, W. Lance y Alexandra Segerberg. "The logic of connective action: Digital media and the personalization of contentious politics". Information, Communication E Society 15.5 (2012): 739-768.

Bennett, W. Lance y Amoshaun Toft. "Identity, technology, and narratives. Transnational activism and social networks". Routledge handbook of Internet politics (2009): 146-260.

Biddix, J. Patrick. "Technology uses in campus activism from 2000 to 2008: Implications for civic learning". Journal of College Student Development 51.6 (2010): 679-693.

Boussard, Caroline. Crafting Democracy. Civil Society in Post-Transition Honduras. Department of Political Science, Lund University, 2003.

Bratich, Jack. "User-generated discontent: Convergence, polemology and dissent". Cultural Studies 25.4-5 (2011): 621-640.

Brewer-Carías, Allan R. "Reforma constitucional, asamblea nacional constituyente y control judicial contencioso administrativo: el caso de honduras (2009) y el antecedente venezolano (1999)". Estudios constitucionales 7.2 (2009): 317-353.

Cálix-Rodríguez, José Á. La emergencia de la sociedad civil en Honduras: la dinámica de la esfera pública no estatal. Tegucigalpa, Honduras: PNUD, 2003.

Cannon, Barry y Mo Hume. "Central America, civil society and the 'pink tide': democratization or de-democratization?". Democratization 19.6 (2012): 1039-1064.

Carasik, Lauren y Azadeh Shahshahani. “'Honduras' presidential election demands an investigation". Al Jazeera America, 28 de noviembre de 2013.

Castells, Manuel. Communication power. Oxford: Oxford University Press, 2013.

Castells, Manuel. The rise of the network society. Oxford: Wiley-Blackwell, 2011.

Cogburn, Derrick L. y Fátima K. Espinoza-Vasquez. “From networked nominee to networked nation: Examining the impact of Web 2.0 and social media on political participation and civic engagement in the 2008 Obama campaign". Journal of Political Marketing 10.1-2 (2011): 189-213. 
Comisión de Verdad y Reconciliación. Tomo I. Para que los hechos no se repitan. Informe de la Comisión de Verdad y Reconciliación, Tomo I, Tegucigalpa, 2011.

Comisionado Nacional de los Derechos Humanos. Los hechos hablan por sí mismos: Informe preliminar sobre los desaparecidos en Honduras 1980-1993. Tegucigalpa, Honduras: Editorial Guaymuras, 1994.

Creswell, John W. Qualitative Inquiry and Research Design: Choosing Among Five Approaches. Los Ángeles: SAGE Publications, 2013.

Davis, Gerald F. et al., eds. Social movements and organization theory. Cambridge University Press, 2005.

Davis, Gerald F. y Mayer N. Zald. "Social change, social theory, and the convergence of movements and organizations". Social movements and organization theory 335 (2005): 350.

Davis, Gerald F. y Mayer N. Zald. "Social change, social theory, and the convergence of movements and organizations". Social movements and organization theory 335 (2005): 350.

Della Porta, Donatella y Hanspeter Kriesi. "Social movements in a globalizing world: An introduction". Social movements in a globalizing world. Palgrave Macmillan, London, 1999. 3-22.

Diario La Prensa. "Arcadia señala ahora a Chimirri. La Prensa 25 de Septiembre 2007. Recuperado de http://www.laprensa.hn/honduras/673952-97/arcadia-se\%C3\%B1alaahora-a-chimirri

Diario Oficial La Gaceta. Sección A. Acuerdos y Leyes. Tegucigalpa, MDC, 26 de septiembre de 2009. N. ${ }^{\circ}$ 32.024).

Dunbar-Hester, Christina. "Beyond "dudecore"? Challenging gendered and "raced" technologies through media activism". Journal of Broadcasting \& Electronic Media 54.1 (2010): 121-135.

Eltantawy, Nahed y Julie B. Wiest. "The Arab spring| Social media in the Egyptian revolution: reconsidering resource mobilization theory". International Journal of Communication 5 (2011): 18.

Espinoza-Vasquez, Fátima K. “Collective Action Framing Episodes: A Methodological Tool to Make Sense of Case Studies" Poster. Association for Information Science and Technology (ASIS\&T) Annual Meeting. Oct. 27, Arlington, VA. 2017.

Espinoza-Vasquez, Fátima K. "More Than Tools: ICTs Influencing Social Movement's Opportunity Structures". The 41st Research Conference on Communication, Information and Internet Policy (TPRC 41) Arlington, VA Sep 27-29. 2013.

Espinoza-Vasquez, Fátima K. "Repression is the Driver of Invention: How the Honduran National Front of Popular Resistance used ICTs to Build Identity, Organize, and Circumvent Censorship". Latin American Studies Association (LASA) Annual Meeting, May 27-30, San Juan, Puerto Rico. 2016.

Fischer, Karin y Dieter Plehwe. "The 'Pink Tide' and Neoliberal Civil Society Formation: Think Tank Networks in Latin America". State of Nature (2013).

Garrett, R. K. "Protest in an information society: A review of literature on social movements and new ICTs". Information, communication \& society 9.02 (2006): 202-224.

Gerbaudo, Paolo. Tweets and the streets: Social media and contemporary activism. Pluto Press, 2018.

Gladwell, Malcolm y Clay Shirky. "From innovation to revolution: Do social media make protests possible?". Foreign Affairs 90.2 (2011): 153.

Gordon, Todd y Jeffery R. Webber. "The Overthrow of a Moderate and the Birth of a Radicalizing Resistance". The New Latin American Left: Cracks in the Empire (2013): 357. 
Grandin, Greg. "Battle for Honduras-and the Region The coup has encouraged those who want to halt the advance of the Latin American left" The Nation (2009).

Granovetter, Mark S. “The strength of weak ties". Social networks. 1977. 347-367.

Grugel, Jean y Pía Riggirozzi. "Post-neoliberalism in Latin America: Rebuilding and reclaiming the State after crisis". Development and Change 43.1 (2012): 1-21.

Hands, Joss. @ is for activism: Dissent, resistance and rebellion in a digital culture. Pluto Press, 2011.

Hayhurst, Lyndsay MC, Brian Wilson y Wendy Frisby. "Navigating neoliberal networks: Transnational Internet platforms in sport for development and peace". International Review for the Sociology of Sport 46.3 (2011): 315-329.

Hess, David J. "Crosscurrents: Social movements and the anthropology of science and technology". American Anthropologist 109.3 (2007): 463-472.

Hogan, John, Peter Nolan y Margaret Grieco. "Unions, technologies of coordination, and the changing contours of globally distributed power". Labor History 51.1 (2010): 29-40.

Howard, Philip N. et al. "Opening closed regimes: what was the role of social media during the Arab Spring?". Project on Information Technology and Political Islam, 2011.

Hsu, Julia Chiung-wen. "Internet and the new civil society movements in taiwan". Hermès, La Revue 3 (2009): 97-105.

Human Rights Watch. World Report 2015: Honduras. (2015). Recuperado de https://www.hrw. org/world-report/2015/country-chapters/honduras

Human Rights Watch. World Report 2018: Honduras. 2018 https:/www.hrw.org/worldreport/2018/country-chapters/honduras

Juris, Jeffrey S. "Reflections on \# Occupy Everywhere: Social media, public space, and emerging logics of aggregation". American Ethnologist 39.2 (2012): 259-279.

Juris, Jeffrey Scott y Geoffrey Henri Pleyers. "Alter-activism: emerging cultures of participation among young global justice activists". Journal of youth studies 12.1 (2009): 57-75.

Kriesi, Hanspeter. "Political context and opportunity". The Blackwell companion to social movements (2004): 67-90.

Kriesi, Hanspeter. "Political context and opportunity". The Blackwell companion to social movements (2004): 67-90.

Leonard, Thomas M. The history of Honduras. ABC-CLIO, 2011.

Loudon, Melissa. "ICTs as an opportunity structure in southern social movements: a case study of the Treatment Action Campaign in South Africa". Information, communication E society 13.8 (2010): 1069-1098.

Maireder, Axel y Christian Schwarzenegger. "A movement of connected individuals: Social media in the Austrian student protests 2009". Information, Communication \& Society 15.2 (2012): 171-195.

McAdam, Doug et al., eds. Comparative perspectives on social movements: Political opportunities, mobilizing structures, and cultural framings. Cambridge University Press, 1996.

McAdam, Doug y Mario Diani. Social movements and Networks: Relational approaches to collective action. Oxford Scholarship Online, 2003.

McAdam, Doug, Sidney Tarrow y Charles Tilly. "Dynamics of contention". Social Movement Studies 2.1 (2003): 99-102.

McCammon, Holly. "Discursive opportunity structure". The Wiley-Blackwell Encyclopedia of Social and Political Movements. Eds. David A. Snow, Donatella della Porta, Bert Klandermans y Doug McAdam. Indianapolis: Wiley-Blackwell, 2013. 
McCarthy, John D. "Constraints and opportunities in adopting, adapting, and inventing". Comparative perspectives on social movements: Political opportunities, mobilizing structures, and cultural framings. Eds. Doug McAdam et al. Cambridge, Cambridge University Press, 1996, 141-151.

Meyer, David S. “Protest and political opportunities". Annu. Rev. Sociol. 30 (2004): 125-145.

Morris, Aldon D. y Carol McClurg Mueller, eds. Frontiers in social movement theory. Yale University Press, 1992.

Nagel, Caroline y Lynn Staeheli. "ICT and geographies of British Arab and Arab American activism". Global Networks 10.2 (2010): 262-281.

Olesen, Thomas. "The transnational Zapatista solidarity network: an infrastructure analysis". Global Networks 4.1 (2004): 89-107.

Peetz, P. "Honduras: A coup that nobody wanted". GIGA Focus Lateinamerika 7 (2009): 1-8.

Pérez, Orlando J., José René Argueta y Mitchell A. Seligson. "Political Culture of Democracy in Honduras, 2010. Democratic Consolidation in the Americas in Hard Times". Nashville: Vanderbilt University (LAPOP, Latin American Public Opinion Project). Recuperado de www. vanderbilt. edu/lapop/honduras/2010-Honduras-Political-Culture.pdf

Pickerill, Jenny. "Symbolic production, representation, and contested identities: Anti-war activism online". Information, Communication \& Society 12.7 (2009): 969-993.

Pilisuk, Marc, JoAnn McAllister y Jack Rothman. "Coming together for action: The challenge of contemporary grassroots community organizing". Journal of Social Issues 52.1 (1996): 15-37.

Portillo-Villeda, Suyapa G. “Organizing Resistance in Honduras: A diverse coalition of social movements continues to resist the imposition of violent neoliberalism, seven years after a coup d'etat removed Honduran president Manuel Zelaya from power". NACLA Report on the Americas 48.3 (2016): 213-216.

Postigo, Hector. "Cultural production and the digital rights movement: Framing the right to participate in culture". Information, communication \& society 15.8 (2012): 1165-1185.

Prevost, Gary, Carlos Oliva Campos y Harry E. Vanden, eds. Social Movements and Leftist Governments in Latin America: Confrontation Or Co-optation? Zed Books Ltd., 2013.

Reitzes, Donald C. y Dietrich C. Reitzes. "Alinsky in the 1980s: Two contemporary Chicago community organizations". Sociological Quarterly 28.2 (1987): 265-283.

Remmer, Karen L. "The rise of Leftist-Populist Governance in Latin America: the roots of electoral change". Comparative Political Studies 45.8 (2012): 947-972.

Riemer, Jeffrey W. "Grass-roots power through internet technology--the case of the crandon mine". Society \& Natural Resources 16.10 (2003): 853-868.

Rivera, Juan Carlos, Eduardo Maldonado de Radio Globo: El pueblo hondureño se ha despertado, Blog: Mirada de Halcón. http://miradadehalconhn.blogspot.com 10 de agosto de 2009.

Ruhl, J. Mark. “Honduras unravels”. Journal of Democracy 21.2 (2010): 93-107.

Russell, Stewart y Robin Williams. "Social shaping of technology: frameworks, findings and implications for policy with glossary of social shaping concepts". Shaping technology, guiding policy: Concepts, spaces and tools. Eds. K. H. Sørensen, R. y Williams. Cheltenham: Edward Elgar Publishing, 2005.

Sádaba, Igor. "Acción colectiva y movimientos sociales en las redes digitales. Aspectos históricos y metodológicos". Arbor 188.756 (2012): 781-794. 
Salomón, Leticia. “Golpe de Estado, clase política y proceso electoral”. LASA forum. Vol. 41. N. 1 . Latin American Studies Association, 2010.

Sánchez, Ilka Treminio. “¿Cómo borrar la letra escrita en piedra? Norma pétrea y reelección presidencial en Honduras". Anuario de Estudios Centroamericanos 42 (2016): 237-260.

Schwartz, Michael y Shuva Paul. "Resource mobilization versus the mobilization of people: why consensus movements cannot be instruments of social change". Frontiers in social movement theory (1992): 205-223.

Scott, Anne. "(In) Forming politics: Processes of feminist activism in the information age." Women's Studies International Forum. Vol. 24. No. 3-4. Pergamon, 2001.

Shumate, Michelle y Jon Pike. "Trouble in a geographically distributed virtual network organization: Organizing tensions in continental direct action network". Journal of Computer-Mediated Communication 11.3 (2006): 802-824.

Sosa, Eugenio. "Honduras: Entre criminalidad, enfrentamiento mediático, protesta social y resultados electorales cuestionados". Revista de ciencia política (Santiago) 34.1 (2014): 203-219.

Sosa, Eugenio. "The movement against the coup in Honduras". Handbook of social movements across latin america. Eds. Paul Almeida y Allen Cordero. New York London: Springer Dordrecht Heidelberg, 2015. 313-326.

Spaeth, Sebastian et al. “Communal resources in open source software development”. Information Research: An International Electronic Journal 13.1 (2008).

Squire, Kurt y Matthew Gaydos. "From Egypt to Wisconsin: tactical innovation with digital media". Critical Studies in Education 54.1 (2013): 57-71.

Tábora, Marlon R. Competencia y regulación de las telecomunicaciones: el caso de Honduras. CEPAL, 2007.

Tarrow, Sidney G. Power in movement: Social movements and contentious politics. Cambridge University Press, 2011.

Taylor-Robinson, Michelle M. “The Honduran general elections of 2009.” Electoral Studies 2.30 (2011): 369-372.

Terco Producciones. (2009). Pieza TV campaña "Cuarta Urna" / Consulta familiar. Recuperado de https://www.youtube.com/watch?v=ANdX1P8fqaYVideo

Tockman, Jason. "The rise of the 'pink tide': Trade, integration, and economic crisis in latin america". Georgetown Journal of International Affairs (2009): 31-39.

Ullman, Richard H. “At war with Nicaragua." Foreign Affairs 62.1 (1983): 39-58.

Van de Donk, Wim, et al. Cyberprotest: New media, citizens and social movements. Routledge, 2004.

Van Laer, Jeroen y Peter Van Aelst. "Internet and social movement action repertoires: Opportunities and limitations". Information, Communication E Society 13.8 (2010): 1146-1171.

Vinthagen, Stellan. “The emergence of social movements' global politics". Sociologisk Forskning 48.1 (2011): 25-50.

Walgrave, Stefaan, et al. "Multiple engagements and network bridging in contentious politics: digital media use of protest participants". Mobilization: An International Quarterly 16.3 (2011): 325-349.

Webber, Jeffery R. y Barry Carr, eds. The new Latin American left: Cracks in the empire. Rowman \& Littlefield Publishers, 2012. 
Weissberg, Robert. "Technology evolution and citizen activism: the net and the rebirth of limited government". Policy Studies Journal 31.3 (2003): 385-395.

Wollenberg, Eva, et al. "Linking social movements: how international networks can better support community action about forests". International Forestry Review 8.2 (2006): 265-272.

Yin, Robert K. Case study research: Design and methods (applied social research methods). London and Singapore: Sage, 2009.

Fátima K. Espinoza-Vasquez. Hondureña. Posee un Doctorado en Ciencias de la Información y Tecnología de la Universidad de Syracuse. Actualmente es Profesora Asistente en la Facultad de Ciencias de la Informacion (iSchool) en la Universidad de Kentucky.

Contacto: fkes222@uky.edu

ORCID: 0000-0001-8808-4824 
